\title{
HIV-1 Protease Inhibitors Resistance Profiles in Patients with Virological Failure on LPV/r-based 2nd Line Regimen in Cambodia
}

Eric Nerrienet ${ }^{1 *}$, Janin Nouhin ${ }^{1}$, Sopheak Ngin ${ }^{1}$, Olivier Segeral ${ }^{2,3}$, Sreymom Ken ${ }^{1}$, Kerya Phon ${ }^{1}$, Chanroeurn Hak ${ }^{2}$, Vara Ouk ${ }^{2}$, Vonthanak Saphonn ${ }^{4}$, Laurent Ferradini ${ }^{5}$ and Jean-Francois Delfraissy ${ }^{3,6}$

${ }^{1}$ HIV/Hepatitis Laboratory, Pasteur Institute, Phnom Penh, Cambodia

${ }^{2}$ ESTHER/Calmette hospital, Phnom Penh, Cambodia

${ }^{3}$ Clinical Immunology Department, Bicetre Hospital, Kremlin Bicetre, France

${ }^{4}$ National Center for HIVIAIDS and STD (NCHADS), Phnom Penh, Cambodia

${ }^{5}$ FHI 360 Cambodia, Phnom Penh, Cambodia

${ }^{6}$ ANRS, Paris, France

\begin{abstract}
Objective: To describe the ARV resistance profiles of patients experiencing virological failure after at least 6 months on $\mathrm{LPV}_{/ \mathrm{r}}$-based $2^{\text {nd }}$ line regimen in Cambodia

Design: Retrospective analysis of resistance testing of 89 patients with detectable viral load under LPV $\mathrm{V}_{/ \mathrm{r}}$-based $2^{\text {nd }}$ line regimen.

Methods: Bulk sequencing of HIV-1 protease, reverse transcriptase and integrase PCR products.

Results: Protease gene amplification was successful for $71 / 89$ patients $(80 \%)$. All were infected by CRF01 AE viruses. Among them, 42 did not present any resistance to PIs. A high level of resistance to Pls was observed for the 29 remaining patients. Twenty-six were resistant to LPV (8 possibly resistant). Twenty-eight, 21 and 20 were also found resistant to IDV, ATVI and FPVI, respectively. Twenty-six were resistant to NFV (11 possibly) and 22 to SQVI, (9 possibly). Finally, 22/29 (75.8\%) were resistant to at least 3 PIs. Interestingly, $78.6 \%$ (22/29) were found sensitive to $\mathrm{DRV} /$. In this group, a high frequency of resistance to RTIs including ETV was also reported. No resistance to raltegravir (RAL) or elvitegravir (EVG) was observed $(n=24)$. Detailed ARV histories documented for 15 patients revealed past exposition to multiple RTIs and PIs.

Conclusion: Almost $2 / 3$ of patients (60/89) with virological failure on LPV $/$-based $2^{\text {nd }}$ line in our study were not in urgent need for treatment change. In contrast, switching treatment was clearly required for $1 / 3(29 / 89)$ presenting high level of resistance to PIs and RTIs. For those patients, DRV, RAL/EVG, and potentially ETV, could be good candidates for $3^{\text {rd }}$ line ARV regimen if available.
\end{abstract}

Keywords: Antiretroviral; Second line; $\mathrm{LPV}_{/ \mathrm{r}}$; Protease and integrase inhibitors; Drug resistance; Cambodia

\section{Introduction}

HAART treatment programs have proven the feasibility and efficacy of first line antiretroviral (ARV) regimen in resource-poor settings to be similar to those reported in developed countries $[1,2]$. In Cambodia, 13.6 million inhabitants, the number of HIV-infected patients on reverse transcriptase inhibitors (RTIs)-based first line ARV regimen increased dramatically these last few years, reaching nearby 41,660 by the end of 2010 [3]. Favourable outcomes were reported in Cambodia among adults and children after one to four years of first line ARV regimen associating AZT or D4T, 3TC/FTC, NVP or EFV [4-7]. At the same time, highly active antiretroviral therapy (HAART) duration is increasing and treatment failures become more common leading to a rising number of patients initiated on second line protease inhibitor (PI)-based HAART regimen. As of end of 2010, the National Centre for HIV/AIDS, Dermatology and STD (NCHADS) reported that nearly 1,800 patients already switched to a protease inhibitor (PI)based $2^{\text {nd }}$ line in Cambodia [8].

Recent WHO recommendations for second line ARV drug regimen include the combination of 2 distinct nucleoside reverse transcriptase inhibitors (NRTI) among didanosine (ddI), abacavir (ABC), tenofovir (TDF) plus lamivudine (3TC), and one ritonavir-boosted protease inhibitor (PI/r) [9].

We recently reported that ritonavir boosted Lopinavir $\left(\mathrm{LPV}_{\mathrm{tr}}\right)$ - based second line ARV regimen in Phnom Penh was associated with a high rate of virological suppression and good immune reconstitution after 24 months of treatment [10].

As expected by the rising number of patients on $\mathrm{LPV}_{/ \mathrm{r}}$-based $2^{\text {nd }}$ line regimen and the extended duration of follow-up on $2^{\text {nd }}$ line regimen, the emergence of $2^{\text {nd }}$ line treatment failures is becoming an important challenge in developing countries with limited virological follow-up and no optional third line regimen [11]. Indeed, mainly because of their price, the number of PI available in these countries remains limited and no integrase inhibitors-based $3^{\text {rd }}$ line ARV regimens are currently available.

The present study aimed to examine the resistance patterns in the protease (PR) gene of HIV-1 in Cambodian patients presenting virological failure on lopinavir boosted ritonavir $\left(\mathrm{LPV}_{/ \mathrm{r})}\right.$-based $2^{\text {nd }}$

${ }^{*}$ Corresponding author: Eric Nerrienet, Ph.D, Institut Pasteur de Paris, Unite RIR, 25 rue du Dr Roux, 75 045, Paris, France, Tel: 336243683 87; Email: enerrien@pasteur.fr

Received May 16, 2012; Accepted June 18, 2012; Published June 20, 2012

Citation: Nerrienet E, Nouhin J, Ngin S, Segeral O, Ken S, et al. (2012) HIV-1 Protease Inhibitors Resistance Profiles in Patients with Virological Failure on LPV/r-based 2nd Line Regimen in Cambodia. J AIDS Clinic Res S5:003. doi:10.4172/2155-6113.S5-003

Copyright: (c) 2012 Nerrienet E, et al. This is an open-access article distributed under the terms of the Creative Commons Attribution License, which permits unrestricted use, distribution, and reproduction in any medium, provided the original author and source are credit ed. 
line regimen). Such information might help to estimate the need for alternative regimen in Cambodia and to design appropriate alternative protease inhibitor (PI)-based $2^{\text {nd }}$ line or integrase inhibitor (II)-based $3^{\text {rd }}$ line regimen in Cambodia.

\section{Material and Methods}

\section{Patients and plasma specimen}

By the end of October 2010, 1,888 blood specimens have been referred for ARV resistance testing as routinely performed at Pasteur Institute of Cambodia (IPC). The nature and the duration of the PIbased therapy were collected and recorded along with the samples. Among 130 patients on LPV/r-based second line regimen, 89 experienced virological failure (VL $>250$ copies $/ \mathrm{ml}$ ) after at least 6 months on $\mathrm{LPV}_{/ \mathrm{r}}$-based $2^{\text {nd }}$ line regimen. Fifty percent of them were patients followed-up by non governmental organizations (NGOs), 30\% were referred by the private sector, and $20 \%$ by national hospitals. Most of them are regularly monitored for HIV VL and resistance testing at IPC.

\section{HIV RNA Viral load (VL)}

Plasma samples were used for HIV RNA viral load (VL) assessment as well as drug resistance genotyping. HIV RNA was extracted from plasma using QIAamp Viral RNA mini kit (Qiagen, Hilden, Germany). The HIV RNA VL was assessed using the G2 Generic HIV-1 viral load ANRS kit (Biocentric, Bandol, France) [12,13]. Using $0.2 \mathrm{ml}$ of plasma, the threshold of the assay was 250 copies $/ \mathrm{ml}$.

\section{HIV Drug Resistance Analysis}

Bulk sequencing of protease (PR), reverse transcriptase (RT) and integrase (IN) genes were performed according to the complete sequencing procedures and primer sequences previously described [14] in order to detect PI, RTI and II resistance associated mutations (RAMs).

Briefly, nested-PCR amplified fragments were sent to the Macrogen Company (Macrogen Inc., Seoul, Republic of Korea) and chromatograms sent electronically to the Pasteur Institute of Cambodia were verified, analyzed, and interpreted using Ceq2000 (Beckman Coulter) software. Nucleotides and amino acid sequences were compared with the HXB2 reference sequence using Mega 4 [15]. Drug resistance mutations were defined according to the last updated ANRS algorithms [14] taking into account the natural genetic polymorphism of CRF01_AE viruses predominant in South East Asia. HIV subtypes were determined by sequence analysis of amplified fragments using CLUSTAL X 1.81 software [16] and subtype reference sequences set from Los Alamos HIV sequence Database.

\section{Nucleotide accession numbers}

Nucleotide sequences of HIV-1 PR, RT, and IN obtained from patients have been submitted to GenBank under the accession numbers JN675743 to JN675813, JN675814 to JN675896, and JN675719 to JN675742, respectively.

\section{Results}

By the end of October 2010, ARV resistance profiles of viruses infecting 89 patients (24 females, 65 males) experiencing virological failure $(\mathrm{VL}>250 \mathrm{cp} / \mathrm{ml})$ after at least 6 months on $\mathrm{LPV}_{/ \mathrm{r}}$ based $2^{\text {nd }}$ line regimen could be retrospectively analyzed. At the time of blood sampling, the median age of these patients was 37 years [IQR: 26.2-41, range 5-64], the median duration on $\mathrm{LPV}_{/ \mathrm{r}}$ was 22 months [IQR: 12-
41, range 6-144] and the median VL was $4.5 \log _{10}$ [IQR: 3.3-5.3, range 2.5-6.8] (Table 1). The most frequent $2^{\text {nd }}$ line regimen prescribed were 3TC-TDF-LPV $(n=24,26.9 \%), 3$ TC-DDI-LPV $(n=15,16.8 \%)$, ABCDDI- $\mathrm{LPV}_{/ \mathrm{r}}(\mathrm{n}=14,15.7 \%), 3 \mathrm{TC}-\mathrm{ZDV}-\mathrm{LPV}_{/ \mathrm{r}}(\mathrm{n}=13,14.6 \%), \mathrm{ZDV}-$ DDI- $\mathrm{LPV}_{/ \mathrm{r}}(\mathrm{n}=5,5.6 \%)$ and $3 \mathrm{TC}-\mathrm{d} 4 \mathrm{~T}-\mathrm{LPV}_{/ \mathrm{r}}(\mathrm{n}=4,4.5 \%)$.

First group of patients with lack of HIV-protease gene amplification (group A)

Three groups of patients could be defined according to their distinct pattern of resistance in the HIV protease genes. The HIV protease gene could not be PCR amplified for 18 ( 16 males and 2 females) of the 89 patients (20.2\%, referred thereafter as group A). Their median duration on $\mathrm{LPV}_{/ \mathrm{r}}$-based $2^{\text {nd }}$ line regimen was 18 months [IQR: 13-27; range 6-45] and the median HIV RNA VL was at $2.9 \log _{10}$ copies/ml [IQR 2.8-3.4; range 2.6-4.1] (Table 1). The most common LPV/r based $2^{\text {nd }}$ line regimen associated TDF or ddI plus 3TC $(\mathrm{n}=11)$ or ABC plus DDI $(n=3)$.

In this group, HIV-RT genes amplification was successful for 12 out of 18. In one case no RTI-RAMs were detected while for the 11 others, the most frequent RTI-RAMs were in positions M184 (7, 38.9\%), T215 (6, 33.3\%), Y181 (6, 33.3\%), M41/K101/G190/L210 (4, 22.2\%) (Figure $2 \mathrm{~A})$. In this group, $50 \%$ of patients were resistant to NVP/EFV, $44.4 \%$ to $3 \mathrm{TC} / \mathrm{FTC}$, and $38.9 \%$ to ZDV/d4T (Figure $2 \mathrm{~B}$ ).

HIV-PR PCR products could be sequenced for the 71 remaining patients (79.8\%). Phylogenetic analysis indicated that all were infected by CRF01_AE viruses commonly found in Cambodia [17-19]. According to the natural genetic polymorphism of CRF01_AE viruses, all these 71 patients harbored viruses with M36I, H69K and/or L89M substitutions known to confer possible resistance to tipranavir $\left(\mathrm{TPV}_{r \mathrm{r}}\right)$ [20-22].

\section{Second group of patients with no resistance to PIs (group B)}

Another group of 42 of 89 (47.2\%), referred thereafter as group B, did not show any resistance to PIs. Their median duration on LPV based $2^{\text {nd }}$ line regimen was 16 months [IQR: 7.2-30.2; range 6-72] and their median HIV RNA VL was $4.8 \log _{10}$ copies/ml [IQR: 4.1-5.4; range 2.7-6.8] (Table 1). The most frequent $\mathrm{LPV}_{/ \mathrm{r}}$-based $2^{\text {nd }}$ regimen prescribed for this group were TDF or ddI plus 3TC $(n=15)$, ABC plus DDI $(n=11)$ or ZDV plus 3TC or DDI $(n=10)$.
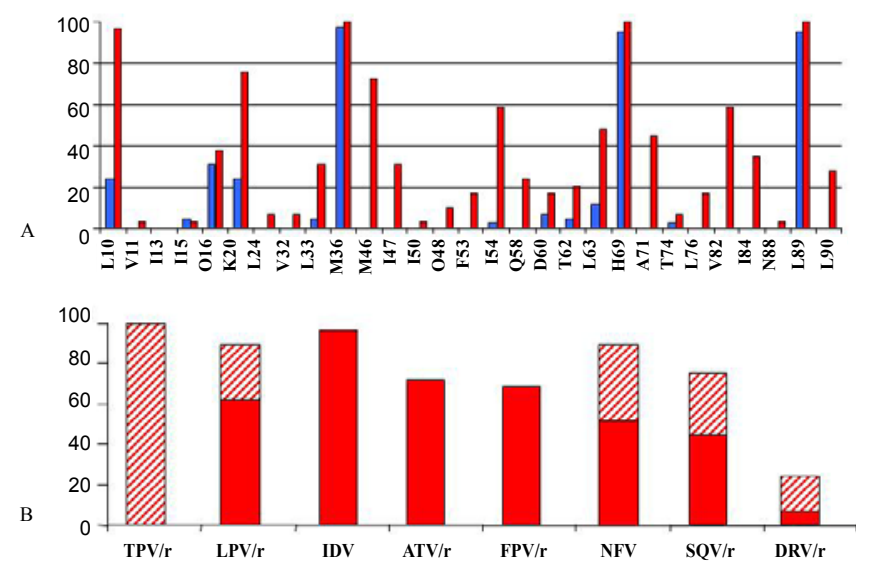

Figure 1: Frequencies of PI-RAMs (1A) and frequencies of resistance to Pls (1B) reported in patients from group B (blue squares), and C (red squares) Asterix indicate the location of the polymorphism mutations (L10, K20, M36, H69 and L89) as reported for CRF01_AE viruses. 
Ten out of these 42 CRF01-AE strains did not present any PI-RAMs in exception of the polymorphic ones as described above. Thirty-two patients had viruses with additional PI-RAMs (Figure 1A) which, however, did not confer resistances to PI according to HIV-1 B subtype algorithms [14] (Figure 1B).

When looking at the HIV RT gene of these patients, RTI-RAMs could not be detected for 20 of these 42 patients (47.6\%). For the 22 remaining patients, the most frequent RTI-RAMs were located in
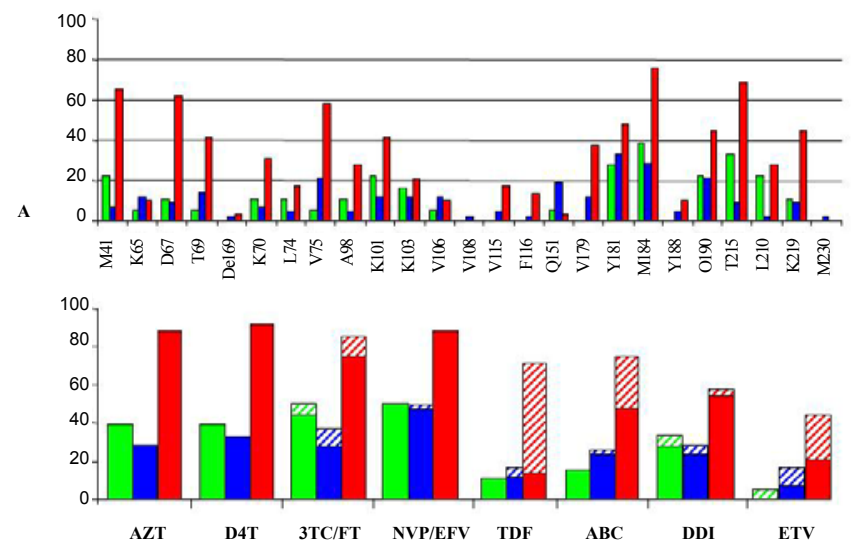

Figure 2: Frequencies of RTI-RAMs (2A) and frequencies of RTIs (2B) detected in patients from group A (green squares), group B (Blue squares) and group $C$ (red squares). positions Y181, M184 and G190 (Figure 2A). RT resistance analysis indicated that 20 of $42(47.6 \%)$ were resistant to NVP/EFV, $14(33.3 \%)$ to $\mathrm{d} 4 \mathrm{~T}, 12(28.6 \%)$ to $\mathrm{ZDV}$ and 12 to $3 \mathrm{TC} / \mathrm{FTC}(28.6 \%)$. Resistance to $\mathrm{ABC}, \mathrm{TDF}$ and ETV were $23.8 \%, 11.9 \%$ and $7.1 \%$, respectively (Figure $2 B)$.

\section{Third group of patient with high level of resistance to PIs (group C)}

A third group of patients $(n=29,32.6 \%)$ presented PI-RAMs conferring resistance to at least one PI (thereafter referred as Group C). The median age in this group was 40 years [IQR: 36-42, range 9-55], the median duration on $\mathrm{LPV}_{/ \mathrm{r}}$-based $2^{\text {nd }}$ line regimen was 35 months [IQR: 24-60, range 9-144] and the median VL was $5 \log _{10}$ copies/ml [IQR: 4.3-5.4; range: 2.5-6.3] (Table 1). In contrast with what was observed for the other groups A and B, a large majority of males $(n=27,93.1 \%)$ was found in this group. Compared with the previous two groups, the median duration on LPV/r was significantly higher $(\mathrm{p}=0.0001)$ (Table 1$)$.

The $\mathrm{LPV}_{/ \mathrm{r}}$-based regimens prescribed in this group were more heterogeneous with some patients receiving ZDV-3TC-TDF-LPV $(\mathrm{n}=3)$ or double PI-based $2^{\text {nd }}$ line regimen including $\mathrm{FPV} / \mathrm{r}-\mathrm{LPV} / \mathrm{r}$ $(\mathrm{n}=1), \mathrm{NFV}_{-\mathrm{LPV}}(\mathrm{n}=1), 3 \mathrm{TC}-\mathrm{SQV} / \mathrm{-LPV}_{/ \mathrm{r}}(\mathrm{n}=1), \mathrm{DDI}-\mathrm{TDF}-\mathrm{SQV} / \mathrm{r}-$ $\operatorname{LPV}_{/ \mathrm{r}}(\mathrm{n}=1)$.

Beside HIV-PR gene polymorphism mutations, the most frequent PI-RAMs observed, were found at positions M46 ( $\mathrm{n}=21,72.4 \%)$, I54 ( $\mathrm{n}=17,58.6 \%)$, V82 ( $\mathrm{n}=17,58.6 \%), \mathrm{L} 63(\mathrm{n}=14,48.3 \%)$ and A71 $(\mathrm{n}=13,44.8 \%)$ (Figure 1A). PI-resistance profile analysis revealed that
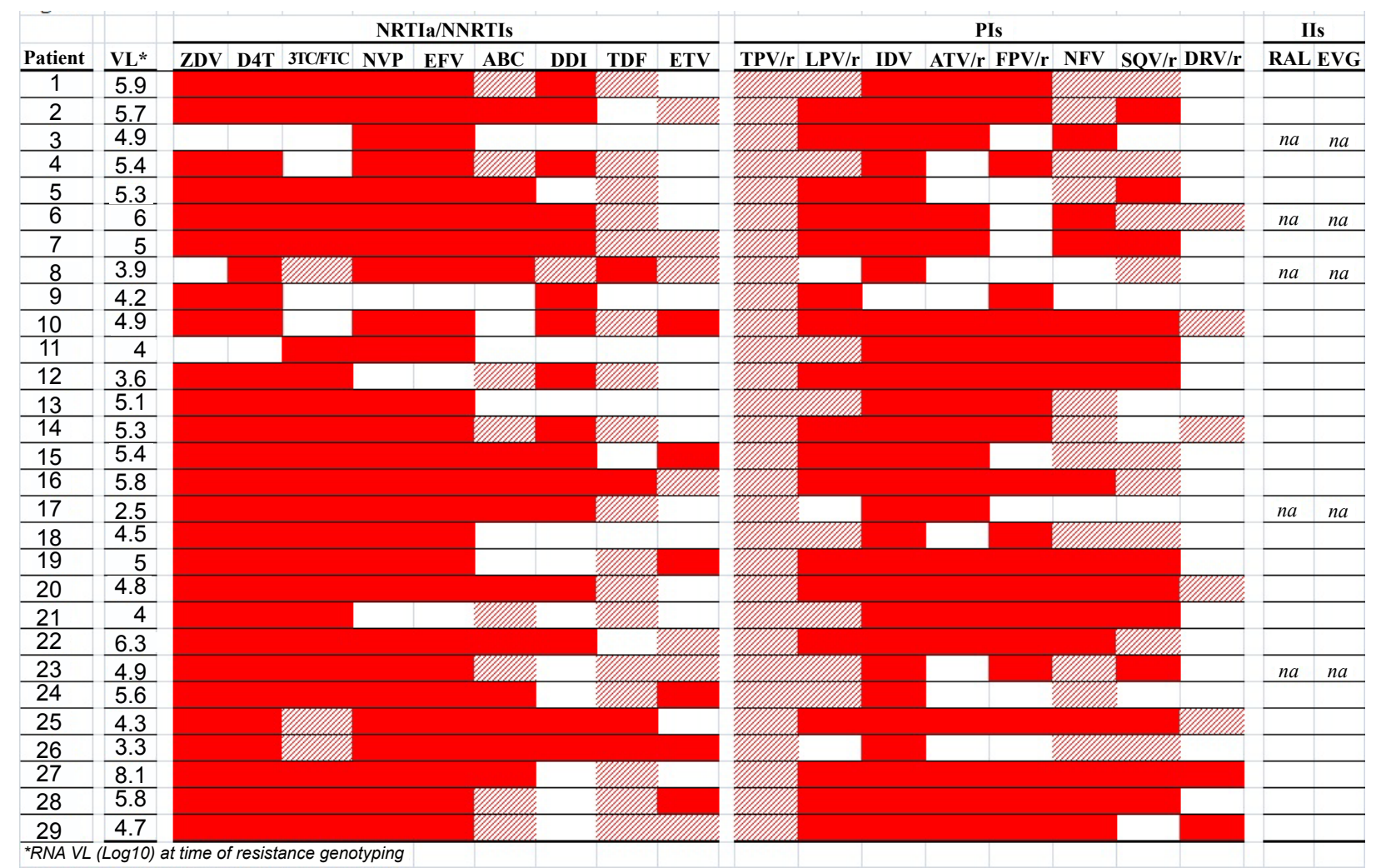

Figure 3: ARV resistance patterns of 29 patients experiencing virological failure and developing at least one resistance to $\mathrm{PI}(\mathrm{group} \mathrm{C}) . \mathrm{Red}$ square $=$ resistant, square red dashed $=$ possibly resistant, white square $=$ sensitive, na $=$ not available. 


\begin{tabular}{|l|l|c|c|c|c|}
\hline & & Total & Group A & Group B & Group C \\
\hline Age (year) & & 89 & 18 & 42 & 29 \\
\hline & Median & 37 & 38 & 29.5 & 40 \\
\hline & {$[$ IQR] } & {$[26.2-41]$} & {$[28-40.7]$} & {$[15.2-39.7]$} & {$[36-42]$} \\
\hline Sex Ratio (M/F) & Range & $5-64$ & $7-56$ & $5-64$ & $9-55$ \\
\hline $\begin{array}{l}\text { Duration on LPV/r } \\
\text { based 2nd line (months) }\end{array}$ & Median & 22.75 & 8 & 1.1 & 13.5 \\
\hline & {$[$ IQR] } & {$[12-43.2]$} & 18 & 16 & 35 \\
\hline & Range & $3-144$ & $6-45$ & {$[7.2-30.2]$} & {$[24-60]$} \\
\hline Median VL (Log10 nb/cp/ml) & Median & 4.5 & 2.9 & 4.8 & $9-144$ \\
\hline & {$[$ IQR] } & {$[3.3-5.3]$} & {$[2.8-3.4]$} & {$[4.1-5.4]$} & $4.3-5.4$ \\
\hline & Range & $2.5-6.8$ & $2.6-4.1$ & $2.7-6.8$ & $2.5-6.3$ \\
\hline
\end{tabular}

Table 1: Main characteristics of the studied patients.

18/29 (62.1\%) were truly resistant to $\mathrm{LPV}_{/ \mathrm{r}}$. True resistance detected among the $18 \mathrm{LPV}_{/ \mathrm{r}}$-resistant patients was due to the selection of the major resistance mutations I47A $(n=3)$ and $\mathrm{L76V}(\mathrm{n}=6)$ or to the accumulation of at least 6 secondary LPV - RAMS among the list proposed by the ANRS [14]. Eight out of $29(27.6 \%)$ were considered only as possibly resistant to LPV . Such possible resistance to LPV was due to the accumulation of 4 to5 PI-RAMs in the list mentioned above. The remaining 3 patients (patients \# 8, \# 17, and \# 26 in Figure 3) were still sensitive to $\mathrm{LPV}_{\text {/r }}$ (Figure 1B) despite presenting detectable viral load (2.5, 3.9 and $3.3 \log _{10}$ respectively) (Figure 3). Sequence analyses indicated that viruses infecting these 3 patients accumulated 2 to $3 \mathrm{LPV}$ -RAMs as well as other PI-RAMs in their protease genes conferring resistance to IDV and $A T V_{/ r}$ for patient 17.

When considering resistances to other PIs (Figure 3, almost all patients $(28 / 29,96.6 \%)$ were found resistant to indinavir (IDV) having selected mutations such as M46I/L $(\mathrm{n}=22), \mathrm{V} 82 \mathrm{~A} / \mathrm{F} / \mathrm{M} / \mathrm{S} / \mathrm{T}(\mathrm{n}=17)$ and/ or I84A/V $(\mathrm{n}=11)$. Twenty-one patients $(72.4 \%)$ were found resistant to atazanavir boosted ritonavir $\left(\mathrm{ATV}_{t \mathrm{r}}\right), 20(68.9 \%)$ to fos-amprenavir boosted ritonavir $\left(\mathrm{FPV}_{\mathrm{rr}}\right), 26(89.6 \%$, including 11 only possibly resistant) to nelfinavir (NFV), $22(75.8 \%$, including 9 only possibly resistant) to saquinavir boosted ritonavir (SQV $)$ and 7 (24.1\%, including 5 only possibly resistant) to darunavir boosted ritonavir $\left(\mathrm{DRV}_{/ \mathrm{r}}\right)$ (Figure $1 \mathrm{~B}$, Figure 3). Concerning DRV $\mathrm{V}_{/ \mathrm{r}}$ resistance, only two patients were found truly resistant since they were infected by viruses harboring more than 13 PI-RAMs in the PR gene. Five other patients were found only possibly resistant to $\mathrm{DRV}_{/ \mathrm{r}}$ while the remaining 22 patients $(75.8 \%)$ were found to be sensitive, despite the presence of 1 $(\mathrm{n}=9)$ or $2(\mathrm{n}=7) \mathrm{DRV} / \mathrm{r}$-RAMs (data not shown).

Globally, as much as 22/29 (75.9\%) and 17/29 (58.6\%) patients harbored viruses resistant to 3 and 4 distinct protease inhibitors, respectively.

When analyzing the HIV RT gene, NNRTIs and NRTIs-RAMs conferring a high level of resistance to RTIs were detected. The most frequent were in positions M184 ( $\mathrm{n}=22,75.9 \%), \mathrm{T} 215(\mathrm{n}=20,69 \%)$, M41 ( $\mathrm{n}=19,66.5 \%), \mathrm{D} 67(\mathrm{n}=18,62.1 \%)$, V75 ( $\mathrm{n}=17,58.6 \%)$, Y181 $(\mathrm{n}=14,48.4 \%), \mathrm{G} 190(\mathrm{n}=13,44.8 \%)$ and K101 $(\mathrm{n}=12,41.4 \%)$ (Figure 2A). Twenty-six patients out of 29 (89.6\%) showed resistance to ZDV, 27 (93.1\%) to D4T, 26 (89.6\%) to EFV and NVP (Fig. 2B, Fig. 3). As indicated in Figure 2B, resistance was also observed to 3TC/FTC for 25 patients (86.2\%, with 3 patients being only possibly resistant), to $\mathrm{ABC}$ for 22 patients (including 8 possibly) and to DDI for 17 (58.6\%, one possibly resistant). Twenty-one (72.4\%) were found resistant to TDF, but 17 of them were considered only possibly resistant. Finally, only 13 patients (44.8\%) were found resistant to ETV (including 6 only possibly resistant) (Figure 2B, Figure 3).
In order to obtain additional information in this group of patients to design either alternative $2^{\text {nd }}$ line or potentially $3^{\text {rd }}$ line regimen, we performed sequencing analysis of the HIV integrase gene for 24 out of the 29 patients. As already described for CRF01_AE viruses [18,23,24], natural polymorphism mutations in the integrase gene were found in positions D10 ( $n=23,95.8 \%), \mathrm{K} 14(\mathrm{n}=23,95.8 \%)$, A21 $(\mathrm{n}=20,83.3 \%)$, V31 ( $\mathrm{n}=22,91.7 \%), \mathrm{S} 39(\mathrm{n}=17,70.8 \%), \mathrm{T} 112(\mathrm{n}=24,100 \%), \mathrm{G} 123(\mathrm{n}=24$, $100 \%)$, T125( $n=24,100 \%)$, R127 ( $=24,100 \%)$, G134 ( $=24,100 \%)$, I135 ( $\mathrm{n}=23,95.8 \%), \mathrm{K} 136(\mathrm{n}=22,91.7 \%), \mathrm{D} 167(\mathrm{n}=13,54.2 \%)$, V201 $(\mathrm{n}=24,100 \%), \mathrm{N} 232(\mathrm{n}=24,100 \%), \mathrm{L} 234(\mathrm{n}=24,100 \%), \mathrm{S} 283 \quad(\mathrm{n}=20$, $83.3 \%$ ) (data not shown). None of these polymorphism mutations are known to be associated with resistance to IIs in HIV-1 B viruses. Four CRF01_AE strains also harbored a V72I II-RAM which, alone, is not sufficient to induce resistance to raltegravir (RAL). Another HIV1 strain presented an amino acid substitution in position 92 (E92K) which is not reported to confer resistance to RAL or EVG. Indeed, only the distinct E92Q substitution is known to be associated to RAL and EVG resistance in HIV B viruses. Finally, none of the mutations observed in the HIV integrase gene could be formally associated to resistance to RAL or EVG (Figure 3) in these patients.

\section{Discussion}

We report here the antiretroviral drug resistance profiles of patients presenting detectable viral load after at least 6 months on LPV -based $2^{\text {nd }}$ line therapy. The first major finding was that no PI resistance was observed for almost two-third of the 89 patients studied outlining the importance of adherence strengthening before envisaging any costly treatment modifications as recently reported [25].

Indeed, the fact that HIV-1 protease PCR amplifications were unsuccessful for $20 \%$ of the patients (group A) could be explained by their low level of VL $(<1,000$ copies/ml, Table 1$)$ below the sensitivity (1000 copies/ml) of the technique used [14] In the group B $(47.2 \%$ of the patients) with no resistance to PIs, some patients had viruses with PI-RAMs which, however, did not confer resistances to PI according to HIV-1 B subtype interpretation algorithms. Even we cannot completely exclude the presence of PI-RAMs in viruses infecting patients of group A, these results suggest that wild type or quasi wild type viruses might have emerged in these patients probably because of recent treatment discontinuation or sub-optimal adherence. All together, these 2 groups of patients with no resistance to PIs represented more than $2 / 3(67.4 \%)$ of patients studied. Interestingly, controlled viral loads performed 6 to 9 months after this first detectable VL revealed that strengthening adherence alone lead to the control of HIV replication for $80 \%$ of them (data not shown).

Thus, in Cambodian settings, where few $2^{\text {nd }}$ line alternatives and no $3^{\text {rd }}$ line regimen are available, focusing on adherence strengthening for patients on $2^{\text {nd }}$ line regimen is critical with a control of the viral load after few months following LPV/r initiation (to detect early poor adherence to $2^{\text {nd }}$ line).

On the other hand, a third group (Group C) representing almost one-third (32.6\%) of the patients displayed multiple resistances to PIs and clearly required urgent treatment modifications. In depth clinical investigations obtained for some of them revealed they all had experienced multiple PI drugs distinct from $\mathrm{LPV}_{/ \mathrm{r}}$ - more than 10 years ago which might have favored the emergence of multiple PI resistance over time. This is similar to the results of first line treatment failures mostly occurring in ARV non-naïve patients in Cambodia $[4,26]$. In addition, the significantly longer period of follow-up on $\mathrm{LPV}_{/ \mathrm{r}}$-based 
regimen in this group compared to the 2 previous groups $(\mathrm{p}=0.001$, Table 1) might have allowed the progressive accumulation of additional protease RAMs over time explaining the complexity of the PI resistance patterns observed.

As expected, almost all of the patients of the group $C$ were resistant to LPV , the PI back-bone of $2^{\text {nd }}$ line regimen in Cambodia. Patients of group $\mathrm{C}$ were also found resistant to many other PIs with the highest number of patient (96.5\%) resistant to IDV. Previous exposure to IDV but also the emergence of cross-reacting mutations, such as $\mathrm{M} 46 \mathrm{I} / \mathrm{L}$, $\mathrm{V} 82 \mathrm{~A} / \mathrm{F} / \mathrm{M} / \mathrm{S} / \mathrm{T}$ and $\mathrm{I} 84 \mathrm{~A} / \mathrm{V}$, under the selective pressure of $\mathrm{LPV}$ might explain such a high level of resistance to IDV. Indeed, IDV together with $\mathrm{SQV}_{/ \mathrm{r}}$ and NFV were easily available in the late 90 s and often prescribed privately or self administered as initial ARV treatment or after first line failure in Cambodia. Many of these patients presented also resistances to other PIs like ATV/r, FPV/r, NFV, SQV/r or DRV/r often to 3 or 4 of them at the same time. Similarly to IDV resistance, such a high level of resistance to several PIs might have been cross-selected under extended $\mathrm{LPV}_{/ \mathrm{r}}$ exposition and also through previous exposure to mostly NFV and/or SQV/r since other PIs including ATV/r, FPV/r, or DRV/r were and are still not or poorly available in the region.

Only $24.1 \%$ of patients from the group C were found resistant to $\mathrm{DRV}_{/ \mathrm{r}}$ (Figure $1 \mathrm{~B}$ ), including $5 / 7$ patients only possibly resistant. Unfortunately, the ARV histories and the small number of patients followed did not allow us to identify risk factors for development

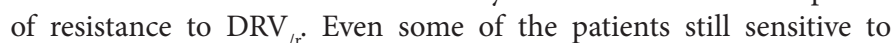
$D V_{/ r}$, have already selected one or two DRV-RAMs, the high level of sensitivity (over 75\%) observed to DRV made it a good candidate for an alternative ARV regimen for this group of patient.

In order to better figure out the type of potential regimen to be proposed to already PI resistant patients, genotyping analysis of the RT and IN genes gave us more information about still available backbone ARV drugs. ETV was the RTI with the lowest level of resistance even with almost $45 \%$ of the patients resistant or possibly resistant, compared to the 25 to $30 \%$ recently reported among HIV-1 infected patients failing first and second line treatment in Mali [27]. It should be also added that, among our patients still sensitive to ETV, some already harbored ETV-RAMs which could jeopardize the future virological efficacy of an alternative therapy combining ETV.

On the other hand, no resistance to integrase inhibitors, such as raltegravir and elvitegravir known to be active against HIV-1 resistant to other classes of antiretroviral drugs [28-33], were detected.

For these patients under confirmed $2^{\text {nd }}$ line treatment failure (group C) an alternative ARV regimen should be considered case per case considering each treatment history. However, if we consider the possibility of a true $3^{\text {rd }}$ line regimen at least, two sensitive ARV drugs should be considered including a new class of ARV, like the integrase inhibitors. As previously reported [29], the combination of DRV/ RAL and potentially ETV could be considered as a $3^{\text {rd }}$ line option. Interestingly, 2 patients (\#28 and \#29, Figure 3 ) who started ETV/DRV/ RAL therapy had an undetectable VL after 3 to 4 months later.

For such patients who currently need to be switched from their $2^{\text {nd }}$ line regimen, the poor availability of alternative ARV class drugs such as ETV/DRV/RAL and its extremely high cost (2000 USD/month) in Cambodia remain dramatic barriers for their survival.

Most of the 29 patients studied here have been previously exposed to several RTI and PI probably at the beginning of the epidemic in Cambodia when ARVs were not yet officially available. It is possible that less people will truly fail to the current $2^{\text {nd }}$ line regimen since the vast majority of patients currently initiated on such regimen through the National Program in Cambodia were ARV-naive before starting first line regimen and probably were never exposed to PIs. This will have to be confirmed by further prospective long term evaluation of $2^{\text {nd }}$ line efficacy in Cambodia.

\section{Acknowledgments}

The authors are grateful to the clinician and to the National Center for HIVIAIDS and STD (NCHADS), Phnom Penh, Cambodia. We warmly thank Y Yazdanpanah for reviewing this manuscript.

Conflicts of interest: EN, JN, SN, OS, SK, KP, CH, VO, VS, LF and JFD declare that they have no competing interests.

This study was presented orally at the International Congress on AIDS in Asia and The Pacific (ICAAP) in Busan, South Korea from August 26 to 30, 2011 (Abstract ID: OP02039).

Author's contribution: EN, JN and JFD conceived of the study design. All authors generated the data. JN, SN, SK and KP performed the analyses and interpretation of data. EN, JN and LF wrote the manuscript.

\section{References}

1. Ivers, LC, Kendrick D, Doucette K (2005) Efficacy of antiretroviral therapy programs in resource-poor settings: a meta-analysis of the published literature. Clin Infect Dis 41: 217-224.

2. Laurent C, Kouanfack C, Koulla-Shiro S, Nkoué N, Bourgeois A, et al. (2004) Effectiveness and safety of a generic fixed-dose combination of nevirapine, stavudine, and lamivudine in HIV-1-infected adults in Cameroon: open-labe multicentre trial. Lancet 364: 29-34.

3. http://www.nchads.org

4. Ferradini L, Laureillard D, Prak N, Ngeth C, Fernandez M, et al. (2007) Positive outcomes of HAART at 24 months in HIV-infected patients in Cambodia. AIDS 21: 2293-2301.

5. Isaakidis P, Raguenaud ME, Te V, Tray CS, Akao K, et al. (2010) High survival and treatment success sustained after two and three years of first-line ART for children in Cambodia. J Int AIDS Soc 13: 11

6. Janssens B, Raleigh B, Soeung S, Akao K, Te V, et al. (2007) Effectiveness of highly active antiretroviral therapy in HIV-positive children: evaluation at 12 months in a routine program in Cambodia. Pediatrics 120: e1134-e1140.

7. Madec Y, Laureillard D , Pinoges L, Fernandez M, Prak N, et al. (2007) Response to highly active antiretroviral therapy among severely immunocompromised HIV-infected patients in Cambodia. AIDS 21: 351-359.

8. http://www.nchads.org/Report/2009\%20q1\%20en.pdf

9. http://www.who.int/hiv/pub/arv/rapid_advice_art.pdf

10. Ferradini L, Ouk V, Segeral O, Nouhin J, Dulioust A, et al. (2011) High efficacy of lopinavir/r-based second-line antiretroviral treatment after 24 months of follow up at ESTHER/Calmette Hospital in Phnom Penh, Cambodia. J Int AIDS Soc 14: 14.

11. Youle M (2007) Overview of boosted protease inhibitors in treatmentexperienced HIV-infected patients. J Antimicrob Chemother 60: 1195-1205.

12. Rouet F, Chaix ML, Nerrienet E, Ngo-Giang-Huong N, Plantier JC, et al (2007) Impact of HIV-1 genetic diversity on plasma HIV-1 RNA Quantification: usefulness of the Agence Nationale de Recherches sur le SIDA secondgeneration long terminal repeat-based real-time reverse transcriptase polymerase chain reaction test. J Acquir Immune Defic Syndr 45: 380-388.

13. Rouet F, Menan H, Viljoen J, Ngo-Giang-Huong N, Mandaliya K, et al. (2008) In-house HIV-1 RNA real-time RT-PCR assays: principle, available tests and usefulness in developing countries. Expert Rev Mol Diagn 8: 635-650.

14. http://www.hivfrenchresistance.org.

15. Tamura K, Dudley J, Nei M, Kumar S (2007) MEGA4: Molecular Evolutionary Genetics Analysis (MEGA) software version 4.0. Mol Biol Evol 24: 1596-1599

16. Thompson JD, Gibson TJ, Plewniak F, Jeanmougin F, Higgins DG (1997) The CLUSTAL_X windows interface: flexible strategies for multiple sequence alignment aided by quality analysis tools. Nucleic Acids Res 25: 4876-4882. 
17. Lan NT, Recordon-Pinson P, Hung PV, Uyen NT, Lien TT, et al. (2003) HIV type 1 isolates from 200 untreated individuals in Ho Chi Minh City (Vietnam): ANRS 1257 Study. Large predominance of CRF01_AE and presence of major resistance mutations to antiretroviral drugs. AIDS Res Hum Retroviruses 19: 925-928

18. Nouhin J, T Donchai T, Hoang KT, Ken S, Kamkorn J, et al. (2010) Natural polymorphisms of HIV-1 CRF01_AE integrase coding region in ARV-naive individuals in Cambodia, Thailand and Vietnam: An ANRS AC12 working group study. Infect Genet Evol 11: 38-43.

19. Ly N, Recordon-Pinson P, Phoung V, Srey C, Kruy LS, et al. (2005) Characterization of mutations in HIV type 1 isolates from 144 Cambodian recently infected patients and pregnant women naive to antiretroviral drugs. AIDS Res Hum Retroviruses 21: 971-976.

20. Bennett DE, Camacho RJ, Otelea D, Kuritzkes DR, Fleury H, et al. (2009) Drug resistance mutations for surveillance of transmitted HIV-1 drug-resistance: 2009 update. PLoS One 4: e4724.

21. Menu E, Reynes JM, Muller-Trutwin MC, Guillemot L, Versmisse P, et al. (1999) Predominance of CCR5-dependent HIV-1 subtype E isolates in Cambodia. J Acquir Immune Defic Syndr Hum Retrovirol 20: 481-487.

22. Nouhin J, Ngin S, Martin PR, Marcy O, Kruy L, et al. (2009) Low prevalence of drug resistance transmitted virus in HIV Type 1-infected ARV-naive patients in Cambodia. AIDS Res Hum Retroviruses 25: 543-545.

23. Eshleman SH, Hudelson SE, Smith P, Hackett J, Holzmayer V, et al. (2009) Analysis of pol integrase sequences in diverse HIV type 1 strains using a prototype genotyping assay. AIDS Res Hum Retroviruses 25: 343-345.

24. Lataillade M, Chiarella J, Kozal MJ (2007) Natural polymorphism of the HIV-1 integrase gene and mutations associated with integrase inhibitor resistance. Antivir Ther 12: 563-570.

25. Wallis CL, Mellors JW, Venter WD, Sanne I, Stevens W (2011) Protease
Inhibitor Resistance Is Uncommon in HIV-1 Subtype C. Infected Patients on Failing Second-Line Lopinavir/r-Containing Antiretroviral Therapy in South Africa. AIDS Res Treat 2011: 769627

26. Ségéral O, Limsreng S, Nouhin J, Hak C, Ngin S, et al. (2011) Short communication: three years follow-up of first-line antiretroviral therapy in cambodia: negative impact of prior antiretroviral treatment. AIDS Res Hum Retroviruses 27: 597-603.

27. Maiga Al, Fofana DB, Cissé M, Diallo F. Daou F (2011) Etravirine resistance mutations among HIV-1 infected patients failing first and second line treatment in Malian cohort in West Africa. $6^{\text {th }}$ IAS conference on HIV Pathogenesis, Treatment and Prevention, Rome, Italy. Abstract TUPE093.

28. De Castro N, Braun J, Charreau I, Pialoux G, Cotte L, et al. (2009) Switch from enfuvirtide to raltegravir in virologically suppressed multidrug-resistant HIV-1infected patients: a randomized open-label trial. Clin Infect Dis 49: 1259-1267.

29. Imaz A, Del Saz SV, Ribas MA, Curran A, Caballero E, et al. (2009) Raltegravir Etravirine, and Ritonavir-Boosted Darunavir: A Safe and Successful Rescue Regimen for Multidrug-Resistant HIV-1 Infection. J Acquir Immune Defic Syndr 52: 382-386.

30. Katlama C, Murphy R (2009) Emerging role of integrase inhibitors in the management of treatment-experienced patients with HIV infection. Ther Clin Risk Manag 5: 331-340.

31. Shimura K, Kodama EN (2009) Elvitegravir: a new HIV integrase inhibitor. Antivir Chem Chemother 20: 79-85.

32. Steigbigel RT, Cooper DA, Kumar PN, Eron JE, Schechter M, et al. (2008) Raltegravir with optimized background therapy for resistant HIV-1 infection. N Engl J Med 359: 339-354.

33. Yazdanpanah Y, Fagard C, Descamps D, Taburet AM, Colin C, et al. (2009) High rate of virologic suppression with raltegravir plus etravirine and darunavir/ ritonavir among treatment-experienced patients infected with multidrug resistant HIV: results of the ANRS 139 TRIO trial. Clin Infect Dis 49: 1441-1449. 